\title{
BRIEFING
}

\section{Covid-19: What do we know about airborne transmission of SARS-CoV-2?}

\section{How covid-19 spreads is one of the most debated questions of the pandemic. Chris Baraniuk explains what the evidence tells us about airborne transmission of the virus}

Chris Baraniuk freelance journalist

\section{What does airborne transmission mean?}

Scientists distinguish between respiratory infectious diseases classed as "airborne"-which spread by aerosols suspended in the air-and infections that spread through other routes, including larger "droplets."

Aerosols are tiny liquid particles from the respiratory tract that are generated when someone exhales, talks, or coughs, for example. They float in the air and can contain live viruses, such as measles and chickenpox. Both are examples of highly infectious diseases classed as airborne because they are known to spread by aerosols.

On the other hand, illnesses such as influenza are thought to spread primarily through larger respiratory droplets. ${ }^{1}$ These do not float as easily and are more likely to fall to the ground within 1-2 $\mathrm{m}$ of the source.

An airborne disease might be more transmissible overall. For example, aerosols produced by infectious person A could build up in a small, poorly ventilated room over time. Person A might depart the room but leave their aerosols behind. If person $B$ were then to arrive in the room and spend time there, they could potentially become infected through breathing in the contaminated air.

But these two modes of transmission-airborne or aerosol based versus droplet-are not necessarily mutually exclusive and the definitions of "droplet" and "aerosol" are a problem. "They should change the terminology," says Julian Tang, consultant virologist at the Leicester Royal Infirmary. ${ }^{2}$ "Droplets hit the ground, they're not inhaled. Everything else is an aerosol when inhaled, whatever size it is."

Advice from the World Health Organization states that aerosols are liquid particles of five microns or less in diameter. In reality, larger particles of moisture can also become suspended for a time in the air, depending on conditions such as temperature and humidity, says Tang. ${ }^{3}$ This means it can be difficult to establish that a virus really has zero opportunity for airborne transmission. 4

\section{Is covid-19 airborne?}

Some scientists have doubted the aerosol route because covid-19 does not appear as transmissible as, say, measles. ${ }^{5}$ But others point to cases of covid-19 transmission where airborne spread appears to be the only explanation behind multiple onward infections.
Sneezing and coughing generally produce larger particles of fluid. But evidence shows large quantities of SARS-CoV-2 are also expelled in small aerosols emitted when someone is speaking at a normal volume, ${ }^{6}$ or merely breathing. One study published in August 2020 found that a single person in the early stages of covid-19 could emit millions of SARS-CoV-2 particles per hour through breathing alone. ${ }^{7}$

Scientists still aren't sure how long viable, infectious virus particles can linger in the air. Tang says this is difficult to study because the devices used to sample air destroy viruses, including SARS-CoV-2. Analysis might detect the virus's RNA but generally find no whole, infectious virus particles. This doesn't mean viable particles were not present-it might simply be that the sampling technique was unable to retrieve them intact.

Despite these unknowns, several case studies suggest airborne transmission has spread SARS-CoV-2 to distances beyond two metres from the infectious person. In a restaurant in Guangzhou, China, 10 people dined on 24 January 2020, shortly before testing positive for covid-19. Three families were seated around three separate tables, but near to each other. One of the families had recently travelled from Wuhan. There was no interaction between the families sitting at their separate tables, nor obvious routes for transmission by touching contaminated surfaces (fomites). A study of the restaurant's ventilation systems, security camera footage, and the case histories of those present concluded that infectious particles carried in the air were likely responsible for the spread of the virus. ${ }^{8}$

Another study, examining an outbreak at an Australian church in July 2020, revealed that a chorister tested positive for covid-19 after developing symptoms. ${ }^{9}$ Researchers identified 12 secondary cases among churchgoers who were linked to the chorister through genomic sequencing of their SARS-CoV-2 infection. Some of these secondary cases had been sitting $15 \mathrm{~m}$ away from the chorister, who was using a microphone and not directly facing those who became infected. The building was minimally ventilated at the time and none of the infected people had worn masks. "We believe that transmission during this outbreak is best explained by airborne spread," the study authors wrote.

A team of researchers recently argued in the Lancet $^{10}$ that aerosols were likely to be the dominant route for transmission for SARS-CoV-2. They based this on 10 
strands of evidence, including the fact that transmission is much higher indoors than outdoors; and that asymptomatic or pre-symptomatic transmission is thought to have caused a significant number of infections worldwide. When someone is not coughing, they may produce fewer droplets but still emit many aerosols.

\section{What does WHO say about airborne transmission of covid-19?}

WHO's roadmap to improve and ensure good indoor ventilation in the context of covid-19, published 1 March $2021,{ }^{11}$ states, "The virus can spread from an infected person's mouth or nose in small liquid particles when the person coughs, sneezes, sings, breathes heavily, or talks. These liquid particles are different sizes, ranging from larger 'respiratory droplets' to smaller 'aerosols.'

"Aerosol transmission can occur in specific situations in which procedures that generate aerosols are performed."

WHO was, however, initially adamant that airborne transmission of SARS-CoV-2 was not possible. The agency tweeted on 28 March 2020, "FACT: \#COVID19 is NOT airborne." (The tweet has not been deleted. WHO told The BMJ that their policy is not to delete any communications.) This sparked much debate-in July 2020, 239 scientists signed an open letter "appealing to the medical community and relevant national and international bodies to recognise the potential for airborne spread of covid-19."12

Since March 2020, WHO has gradually changed its stance. At the time of writing, its official advice reads, "Airborne transmission of SARS-CoV-2 can occur during medical procedures that generate aerosols."13

Nick Wilson, an anaesthetist at the Royal Infirmary in Edinburgh, questions the emphasis on medical procedures. "Procedures don't generate many aerosols, people do, the physiology does," he says. ${ }^{14}$ He also points to a 2014 WHO report which noted that, for any novel acute respiratory infections that have a high public health risk, "airborne and contact precautions, as well as eye protection, should be added to the routine standard precautions whenever possible, to reduce the risk of transmission." Precautions include ventilation and spacing of patients. ${ }^{15}$

According to WHO, in reply to BMJ questions, “Outside of medical facilities, aerosol and airborne transmission can occur in specific circumstances and settings, particularly indoor, crowded, and inadequately ventilated spaces such as restaurants, fitness classes, nightclubs, offices, and places of worship, where infected people spend long periods of time with others."

The agency added that the term "airborne" has a specific medical meaning that applies to diseases such as measles, which transmit predominantly through the air and across long distances. "For covid-19," WHO added, "the virus predominantly spreads through close, or direct, contact, or possibly contaminated surfaces. That is why it is not called an airborne virus."

In other words, the agency is currently of the opinion that viral transmission by aerosols, while possible for covid-19, is not the main route by which SARS-CoV-2 spreads.

\section{What do national governments say about airborne transmission of covid-19?}

At the time of writing, UK advice states that covid-19 spreads "through the air by droplets and smaller aerosols" and notes that infectious particles can "remain suspended in the air for some time indoors, especially if there is no ventilation." ${ }^{16}$ The government's main public safety messaging of "hands, face, space," to remind people to wash their hands, wear face masks, and keep distant from one another, was recently updated to include "fresh air," to encourage people meeting to stay outdoors.

In the US, the Centers for Disease Control and Prevention (CDC) updated its advice on 5 October 2020, acknowledging "the existence of some published reports showing limited, uncommon circumstances where people with covid-19 infected others who were more than 6 feet away or shortly after the covid-19-positive person left an area. In these instances, transmission occurred in poorly ventilated and enclosed spaces that often involved activities that caused heavier breathing, like singing or exercise. Such environments and activities may contribute to the build-up of virus carrying particles." 17

Other countries, such as Australia, make no mention of airborne or aerosol based transmission in their official guidance on how covid-19 spreads.

\section{How can we prevent airborne transmission?}

Advice from governments includes ventilation-such as opening windows-and avoiding enclosed spaces. Japan puts emphasis on avoiding the " 3 Cs": crowded places, close contact, close conversations - this is echoed in WHO communications that emphasise location, proximity, and time. There is some evidence for this from modelling studies. In one, researchers estimated that the risk of infection could be three times higher in a poorly ventilated room as opposed to one that underwent 10 air changes per hour. ${ }^{18}$

The installation of air filtering units such as those with high efficiency particulate air filters or specialised ventilation systems could also help. This may be one reason why some governments are reluctant to officially declare SARS-CoV-2 "airborne," says Catherine Noakes, professor of environmental engineering for buildings at the University of Leeds. "If you think something transmits on surfaces, it's easy to do a precautionary approach and tell everybody to wash their hands. But if we say it's in the air, that means some quite major capital investments to buildings and technologies," she says. Installing energy hungry systems has environmental downsides too.

\section{Do masks prevent airborne transmission?}

Some have claimed that airborne transmission would mean face masks were ineffective, since aerosols carrying the virus might pass through microscopic holes in the cloth of a mask. But Noakes says the heightened humidity inside a face mask could help to catch these particles, should they be emitted by the wearer.

She adds that cloth masks-unlike filtering masks such as the N95-may offer only limited protection against breathing in aerosols if they are already suspended in the air. Tang notes that tighter fitting masks or wearing two masks might reduce the emission of aerosols from a source and the inhalation by a recipient wearer.

Still, Wilson says looser fitting masks block or deflect most exhaled air, which reduces its velocity.

\section{How does airborne transmission compare outdoors versus indoors?}

There is a risk of covid-19 transmission outdoors, but it is low compared with indoor settings.

In the summer of 2020 , widely reported gatherings on British beaches were condemned by some who assumed these events would lead to a spike in covid-19 transmission. In February this year, 
however, Mark Woolhouse, professor of infectious disease epidemiology at the University of Edinburgh, who has advised the government during the pandemic, told MPs, "There were no outbreaks linked to public beaches. There's never been a covid-19 outbreak linked to a beach, ever, anywhere in the world, to the best of my knowledge."

Babak Javid, associate professor of medicine at the University of California, San Francisco, argues that it's time to offer a more nuanced message to the public. Various interventions offer protection he says, but it's also important to recognise that the risks of particular environments may differ. "If you're wearing masks, you probably can tolerate a shorter distance between people," he says, "If you're outdoors you can be closer to people. If you're indoors, distance by itself won't be protective, necessarily."

Commissioned, not externally peer reviewed.

Competing interests: I have read and understood BMJ policy on declaration of interests and have no relevant interests to declare.

1 CDC. How flu spreads. www.cdc.gov/flu/about/disease/spread.htm.

2 Tang JW, Bahnfleth WP, Bluyssen PM, et al. Dismantling myths on the airborne transmission of severe acute respiratory syndrome coronavirus-2 (SARS-CoV-2). J Hosp Infect 2021;110:89-96. doi: 10.1016/j.jhin.2020.12.022 pmid: 33453351

3 Tang JW. The effect of environmental parameters on the survival of airborne infectious agents. J R Soc Interface 2009 Dec 6;(suppl 6):S737-46.

4 Yan J, Grantham M, Pantelic J, et alEMIT Consortium. Infectious virus in exhaled breath of symptomatic seasonal influenza cases from a college community. Proc Natl Acad Sci U S A 2018;115:1081-6. doi: 10.1073/pnas.1716561115 pmid: 29348203

5 Klompas M, Baker MA, Rhee C. Airborne transmission of SARS-CoV-2: theoretical considerations and available evidence. JAMA 2020;324:441-2. doi: 10.1001/jama.2020.12458 pmid: 32749495

6 Stadnytskyi V, Bax CE, Bax A, Anfinrud P. The airborne lifetime of small speech droplets and their potential importance in SARS-CoV-2 transmission. Proc Natl Acad Sci U S A2020;117:11875-7. doi: 10.1073/pnas.2006874117 pmid: 32404416

7 Ma J, Qi X, Chen H, et al. COVID-19 patients in earlier stages exhaled millions of SARS-CoV-2 per hour. Clin Infect Dis 2020:ciaa1283. doi: 10.1093/cid/ciaa1283 pmid: 32857833

8 Li Y, Qian H, Hang J, et al. Probable airborne transmission of SARS-CoV-2 in a poorly ventilated restaurant. Build Environ2021;196:107788. doi: 10.1016/j.buildenv.2021.107788 pmid: 33746341

9 Katelaris AL, Wells J, Clark P, et al. Epidemiologic evidence for airborne transmission of SARS-CoV-2 during church singing, Australia, 2020. Emerg Infect Dis 2021;27. doi: 10.3201/eid2706.210465 pmid: 33818372

10 Greenhalgh T, Jiminez JL, Prather KA, Tufekci Z, Fisman D, Schooley R. Ten scientific reasons in support of airborne transmission of SARS-CoV-2. Lancet2021;Apr 15:S0140-6736(21)00869-2.

11 WHO. Roadmap to improve and ensure good indoor ventilation in the context of covid-19.1 March 2021. www.who.int/publications/i/item/9789240021280.

12 Morawska L, Milton DK. It is time to address airborne transmission of covid-19. Clin Infect Dis 2020;71:2311-3.pmid: 32628269

13 WHO. Transmission of SARS-CoV-2: implications for infection prevention precautions. 9 July 2020. www.who.int/news-room/commentaries/detail/transmission-of-sars-cov-2-implicationsfor-infection-prevention-precautions.

14 Wilson NM, Marks GB, Eckhardt A, et al. The effect of respiratory activity, non-invasive respiratory support and facemasks on aerosol generation and its relevance to COVID-19. Anaesthesia2021. doi: 10.1111/anae.15475. pmid: 33784793

15 WHO. Infection prevention and control of epidemic-and pandemic-prone acute respiratory infections in health care. 2014. www. who.int/publications/i/item/infection-prevention-and-controlof-epidemic-and-pandemic-prone-acute-respiratory-infections-in-health-care.

16 Public Health England. How to stop the spread of coronavirus (covid-19). 31 March 2021. www.gov.uk/government/publications/how-to-stop-the-spread-of-coronavirus-covid-19/howto-stop-the-spread-of-coronavirus-covid-19.

17 CDC. How covid-19 spreads. 2020. www.cdc.gov/coronavirus/2019-ncov/prevent-gettingsick/how-covid-spreads.html.

18 de Oliveira PM, Mesquita LCC, Gkantonas S, Giusti A, Mastorakos E. Evolution of spray and aerosol from respiratory releases: theoretical estimates for insight on viral transmission. Proc Math Phys Eng Sci 2021:477:20200584. doi: 10.1098/rspa.2020.0584 pmid: 33633490

This article is made freely available for personal use in accordance with BMJ's website terms and conditions for the duration of the covid-19 pandemic or until otherwise determined by BMJ. You may download and print the article for any lawful, non-commercial purpose (including text and data mining) provided that all copyright notices and trade marks are retained. 